\title{
Public Preferences in Priority Setting when Admitting Patients to the ICU During the COVID-19 Crisis: A Pilot Study
}

\author{
Merle Gijsbers $^{1}$ - Iris Elise Keizer ${ }^{1}$ - Stephanie Else Schouten ${ }^{1}$. Janneke Louise Trompert ${ }^{1}$. \\ Catharina G. M. Groothuis-Oudshoorn ${ }^{2}$. Janine Astrid van Til ${ }^{2}$
}

Accepted: 28 February 2021 / Published online: 22 March 2021

(c) The Author(s) 2021

\begin{abstract}
Introduction One of the challenges faced by hospitals during the coronavirus disease 2019 (COVID-19) pandemic is resource shortages in intensive care units (ICUs). In times of scarcity, patient prioritization based on non-medical considerations might be necessary.

Objective The aim of this study was to pilot test a survey to elicit public opinions on the relative importance of non-medical considerations in priority setting when admitting patients to the ICU in times of crisis.

Methods A discrete-choice experiment was used to collect social preferences for priority setting when admitting patients to the ICU during the COVID-19 pandemic. The six attributes were patient age, profession, guardianship, risk-conscious behavior on a societal level, health-conscious behavior, and expected ICU length of stay. The data were analyzed using a mixed multinomial logit model. Interactions between the age and profession of the respondents and the age and profession of the patient profiles were considered. Results The mean ( \pm standard deviation) age of respondents was $35.9 \pm 14.5$ years. In all, $70 \%$ of respondents indicated that medical and/or non-medical considerations should play a role in prioritizing patients for the ICU, whereas $15 \%$ agreed with a "first come, first served" strategy and the remaining $15 \%$ had no opinion. Respondents deemed risk-conscious behavior on a societal level to be the most important non-medical factor that should be used to prioritize patients in phase three of the framework, garnering an attribute importance (AI) of 31.2\%, followed by patient age (AI 16.3\%) and health-conscious behavior (AI 16.0\%). ICU length of stay had the lowest impact on patient prioritization for ICU admittance (AI 10.9\%). Younger and older respondents attached more importance to age than respondents in the middle age group and indicated a stronger preference to prioritize patients in their own age group $(p=0.042)$.

Conclusion The results of our study demonstrate the relative importance members of the public attach to responsible societal behavior during the COVID-19 pandemic. In the next phase of the study, we will elicit the perspectives of a representative sample of the Dutch population. Changes to the task design and attribute operationalization could improve the external validity of the study findings, and optimization of the experimental design will improve the internal validity of the study.
\end{abstract}

\section{Key Points for Decision Makers}

When triaging patients with coronavirus disease 2019 (COVID-19) for admission to the intensive care unit (ICU) based on non-medical considerations, public

The first four authors contributed equally to the paper.

Janine Astrid van Til

j.a.vantil@utwente.nl

1 Educational Program Health Sciences, Science and Technology, University of Twente, Enschede, The Netherlands

2 Department of Health Technology and Services Research, Technical Medical Center, University of Twente, Drienerlolaan 5, 7522 NB Enschede, The Netherlands opinion should be considered to create a situation of coownership.

The public deemed individual responsibility as important for priority setting even though medical professionals consider this unethical and impractical.

This pilot study provides valuable information on the trade-offs necessary for ICU priority setting, which can support future research on this ethically complex topic. 


\section{Introduction}

Since severe acute respiratory syndrome coronavirus 2 (SARS-CoV-2) emerged in December 2019, it has taken the world by storm. In November 2020, the total number of confirmed cases of coronavirus disease 2019 (COVID19) worldwide was $61,715,119$ cases (including $1,444,235$ deaths), and the number was continuing to rise [1]. The virus and the national measures that were necessary to contain it have affected the lives of both individuals and society. Examples of such measures in the Netherlands include working from home, hygiene rules, social-distancing rules, and instructions to avoid crowded places [2].

One of the primary drivers for implementing the national measures was to prevent resource shortages in hospital intensive care units (ICUs) as this may create problems for access to care for those in need and healthcare inequity. Resource shortages were one of the main challenges faced by hospitals during the first infection peak in March-April 2020. During this time, nearly full occupancy of ICU beds was reached (even after upscaling the national ICU bed capacity from 1150 to 1700) [3]. The Netherlands acted upon their care alliance with Germany, whereby patients who were unable to receive treatment in Dutch hospitals were transported to German hospitals for critical care [4]. As such, prioritization decisions were avoided during the first wave.

In preparation for a second wave of the virus, a triage framework for admitting patients into the ICU was developed on the request of the federation of medical specialists in The Netherlands. The first step of this framework consists of reconstructing other departments into ICUs, specifically for crisis situations. The second step is to prioritize patients based on medical reasons that influence expected survival. The last step consists of triage based on non-medical reasons [5]. In developing the third step, medical specialists of different associations and professors in medical ethics and philosophy were consulted.

Both the second and the third step of this protocol involve preference-sensitive decisions in which the decision to prioritize is influenced by the relative importance that decision makers attach to the different arguments included. For the second step, ICU physicians and other medical professionals are the experts, as they are most experienced in estimating the impact of individual patient characteristics on patient prognosis. However, we argue that, in developing the third step of the protocol, including a societal perspective on relevant factors to include and their relative importance could support medical professionals and policy makers in making an informed decision about which arguments to include. It could create a situation of co-ownership of the potential consequences of the decision-making process.
Within the last year, Wilkinson et al. [6] and Asghari et al. [7] have studied public preferences in the UK and Iran, respectively, for the treatment of patients with COVID19 when only one ventilator is available. Wilkinson et al. [6] included the chance of survival, life expectancy, age, expected length of treatment, disability, and degree of frailty as arguments and found that the most important reasons for prioritization in the UK were higher chance of survival, a longer life expectancy, and a shorter duration of treatment. This study did not include non-medical arguments [6]. Asghari et al. [7] included 11 medical- and non-medical arguments, namely, likelihood of survival, duty to care, quality of life, reassessment of the patient, the "first come, first served" basis, social support, financial ability, political position, reciprocity, sex, and age. They found that having a medical profession was the most important factor that determined prioritization decisions, and it was more important than better prognosis [7]. However, the findings in these studies do not easily translate to the Dutch context because of differences in healthcare and political systems.

The aim of this study was to pilot a survey to elicit public perspectives on the relative importance of non-medical considerations that influence prioritization for ICU beds during the COVID-19 pandemic in the Netherlands. In this study, we used a discrete-choice experiment (DCE) to elicit preferences. A DCE is a stated-preference method for studying the preferences of patients and other stakeholders. It has become the most frequently applied approach in healthcare to determine preferences for health and non-health attributes of care [8]. This methodology explicitly emphasized the trade-offs that must be made in making prioritization decisions.

\section{Methods}

\subsection{Study Population}

To elicit the societal preferences, an online health preference survey was conducted in the Netherlands in October 2020. Survey participants were recruited through convenience sampling. The survey was advertised online via the researchers' social media accounts (i.e., LinkedIn and WhatsApp). Subsequent snowball sampling might have occurred when this advertisement was shared further. No inclusion or exclusion criteria were put in place.

\subsection{Attributes and Levels}

A narrative literature search was conducted to determine which non-medical attributes were potentially relevant to priority setting for the ICU from a public perspective in the Netherlands. Different combinations and Dutch translations 
of terms equivalent to "COVID-19", "priority setting," and "intensive care" were entered into PubMed, Google Scholar, and Scopus. Scientific abstracts on ICU prioritization, both COVID and non-COVID related, were read to identify relevant studies. Reference lists were checked for other suitable studies. From 18 articles, 14 attributes were extracted. After discussion between the researchers, a final list of six attributes remained. Attributes that embodied medical considerations and attributes that were redundant, overlapping, or preferentially dependent were excluded (Appendix A in the electronic supplementary material [ESM]). The final six attributes were age, profession, guardianship, expected ICU length of stay (ICU stay), risk-conscious behavior on a societal level, and health-conscious behavior. Age, profession, and ICU stay were extracted from the third step of the triage framework [5]. The other attributes (guardianship, risk-conscious behavior on a societal level, and individual health-conscious behavior) were based on public discussions about COVID-19 and prioritization of ICU beds in the media $[9,10]$. Each attribute was operationalized using three levels. In phrasing the attributes and their levels, care was taken to avoid the use of medical jargon and to keep the terminology simple for easy interpretation in order to increase response efficiency. The levels for ICU length of stay were based on the average ICU stays of patients with and without COVID$19[11,12]$. The final choice of attributes and their levels are shown in Table 1.

\subsection{Survey Design}

In the survey, respondents were presented with a series of choice tasks and asked to choose between two patient profiles. These patient profiles contained the same attributes but showcased different combinations of attribute levels, making each profile unique. Based on the respondent's preferences for one of the two profiles, their trade-offs and preferences could be determined via the relative importance of each attribute and attribute level [13].

The full factorial design of the survey consisted of 729 potential profiles. To increase the response efficiency and lower the cognitive burden for respondents, a fractional factorial experimental design was chosen for this study and constructed using the rotation.design (package support. CEs, version 0.4-1) function in $\mathrm{R}$ (version 3.6.3) [14, 15]. Rotation.design was used to generate a choice experiment design according to the mix-and-match method [16]. In the mix-and-match method, two sets of an 18-alternative main effects array were created, and a choice set was generated by randomly combining two alternatives, one from each set [15]. This introduced overlap in the attribute levels of the choice tasks.
Table 1 Attributes and levels

\begin{tabular}{ll}
\hline Attributes & Levels \\
\hline Age, years & $\leq 29,30-59, \geq 60$ \\
Profession & $\begin{array}{c}\text { Medical, crucial, } \\
\text { non-medical and } \\
\text { non-crucial }\end{array}$ \\
& Sole, shared, none \\
Guardian and/or caregiver & $4,8,12$ \\
ICU length of stay, days & High, moderate, low \\
Risk-conscious behavior on a societal level & High, moderate, low \\
Health-conscious behavior &
\end{tabular}

$I C U$ intensive care unit

To further increase the response efficiency and to prevent fatigue, nine choice sets per respondent were randomly selected from the total set of 18. As a result, both the choice sets and the order in which the choice sets were presented varied per respondent.

The survey was programmed in Qualtrics. The first page of the survey consisted of an introduction of the study and an explanation of the attributes. After the introductory page, respondents were presented with the DCE questions. Qualtrics did not allow the survey to proceed until all assigned DCE questions were completed. This ensured that respondents filled in every question before they moved on to the next page. As a result, only completed surveys were included in the statistical analysis. After completing the DCE, respondents filled out three background questions on age, sex, and profession. To gather overall opinions on priority settings in the ICU in times of resource scarcity, respondents chose their preferred method of prioritization: "medical and/or non-medical considerations should play a role when prioritizing patients", "prioritization of patients should take place according to the rule 'first come, first served'," or "no opinion".

Before finalizing the survey, a pre-test was carried out with five test respondents. This test did not result in changes to the survey, so a final version of the survey was distributed. The translated version of the survey can be seen in Appendix $\mathrm{B}$ in the ESM; its original language was Dutch.

To determine an adequate sample size to predict preferences, the rule of thumb of Orme was used [17]. With this formula, 84 respondents were needed to be able to predict preferences.

\subsection{Statistical Analysis}

The data were analyzed using a mixed logit model. This model was chosen because it accounts for preference heterogeneity among respondents and makes it possible to derive individual-specific estimates based on the observed respondent [18]. The likelihood ratio test (lrtest, version 
0.9-37) showed that the mixed logit model was significantly better than the conditional logit model for the analysis $(p<$ 0.001). Normal distributions were used for all parameters, and the number of random draws was 100. Except for the continuous attribute "ICU stay", the attribute levels were effects coded. The primary outcome of this model was the beta coefficients, which estimated the part-worth utility for each attribute level. With the beta coefficients, the attribute weights were calculated using the method proposed by Gonzalez [19]. The attribute weights were then multiplied by 100 to portray the relative attribute importance as percentages (Table 3) [19].

We hypothesized that the age of the respondent would influence the preference for the age attribute, as respondents might prioritize patients within their own age group. Likewise, we hypothesized that individuals working in the medical profession would show bias towards the profession attribute. To assess whether preferences differed according to the age and profession of the respondent, we also estimated the model with interaction effects between these respondent characteristics and the corresponding attributes.

All statistical analyses were conducted with $\mathrm{R}$ (version 3.6.3), and the package used for the mixed logit model was mlogit (version 1, 1-0). The level of statistical significance was set to 0.05 for all statistical analyses.

\section{Results}

\subsection{Respondents}

A total of 341 respondents started the survey; 243 completed the survey, resulting in a response rate of $71.3 \%$. Of these respondents, $28.5 \%$ were male and $71.5 \%$ were female. The mean ( \pm standard deviation) age was $35.9 \pm 14.5$ years (range 15-78). Of the respondents, 70 (28.8\%) worked in a medical profession, 36 (14.8\%) worked in a crucial profession, and 137 (56.6\%) worked in neither a medical nor a crucial profession. An overview of the respondent characteristics can be found in Table 2.

\subsection{Opinion on Priority Settings on the Intensive Care Unit}

Of the 243 respondents, 170 (70.2\%) felt that medical and/ or non-medical considerations should play a role when prioritizing patients. On the other hand, 35 (14.5\%) felt that prioritization of patients should take place according to the rule "first come, first served". The remaining 37 respondents (15.3\%) had no opinion.

\subsection{Within-Attribute Importance}

The results of the mixed logit model are presented in Table 3. The estimates of the beta coefficients for the attributes age, profession, guardianship, ICU stay, and riskconscious behavior on a societal level were in line with the expected ordering. All attributes were significant determinants for the preference of the patient that is prioritized. For the attribute age, respondents prioritized patients aged $\leq 29$ years $(\beta=0.694, p<0.001)$ over patients aged $\geq 60$ years $(\beta=-0.822, p<0.001)$. For risk-conscious behavior on a societal level, a high level of risk-conscious behavior had a higher positive coefficient $(\beta=1.368, p<0.001)$ and was thus preferred over low levels of risk-conscious behavior $(\beta$ $=-1.528$ ). ICU stay had a significant and expected negative effect on prioritizing patients. A longer ICU stay resulted in a larger negative coefficient $(\beta=-0.126, p<0.001)$.

For the attribute "health-conscious behavior", respondents' preferences were not in line with the expected ordering. Moderate health-conscious behavior had the highest positive coefficient $(\beta=0.676, p<0.001)$ and was therefore the most preferred attribute level, instead of high levels of healthconscious behavior $(\beta=0.136)$.

Table 2 Respondent characteristics

\begin{tabular}{ll}
\hline Characteristics & Results $^{\mathrm{a}}$ \\
\hline Sex & \\
Male & $69(28.5)$ \\
Female & $173(71.5)$ \\
Age, years & \\
Range & $15-78$ \\
Mean \pm standard deviation & $35.9 \pm 14.5$ \\
$\leq 29$ & $111(45.9)$ \\
$30-59$ & $114(47.1)$ \\
$\geq 60$ & $17(7.0)$ \\
Profession & \\
Medical profession & $70(28.9)$ \\
Crucial profession & $35(14.5)$ \\
Non-medical and non-crucial profession & $105(43.4)$ \\
No profession & $32(13.2)$ \\
Prioritizing in healthcare & \\
Medical and non-medical considerations need to be & $170(70.2)$ \\
$\quad$ taken into account & \\
"First come, first served" principle & $35(14.5)$ \\
No opinion & $37(15.3)$ \\
\hline
\end{tabular}

${ }^{\text {a}}$ Data are presented as $n(\%)$ or mean \pm standard deviation unless otherwise indicated 
Table 3 Results of mixed logit model and attribute importance

\begin{tabular}{|c|c|c|c|c|c|c|}
\hline \multirow[t]{2}{*}{ Attributes } & \multirow[t]{2}{*}{ Level } & \multicolumn{3}{|c|}{ Mixed logit model } & \multicolumn{2}{|l|}{ SD } \\
\hline & & $\begin{array}{l}\text { Part-worth } \\
\text { utility }\end{array}$ & SE & $\begin{array}{l}\text { Attribute } \\
\text { importance } \\
(\%)\end{array}$ & $\begin{array}{l}\text { Part-worth } \\
\text { utility }\end{array}$ & SE \\
\hline \multirow[t]{3}{*}{ Age (years) } & $\leq 29$ & $0.694 * * *$ & 0.084 & 16.3 & 0.043 & 0.203 \\
\hline & $30-59 *$ & 0.128 & 0.094 & & - & \\
\hline & $\geq 60$ & $-0.822 * * *$ & 0.104 & & $0.517 * * *$ & 0.109 \\
\hline \multirow[t]{3}{*}{ Profession } & Medical & $0.497 *$ & 0.100 & 13.4 & $0.335^{*}$ & 0.143 \\
\hline & Crucial & $0.250 * *$ & 0.159 & & $0.428 * *$ & 0.134 \\
\hline & $\begin{array}{l}\text { Non-medical } \\
\text { and non- } \\
\text { crucial* }^{*}\end{array}$ & $-0.747 * *$ & 0.218 & & - & \\
\hline \multirow[t]{3}{*}{ Guardian and/or caregiver } & Sole & $0.545 * * *$ & 0.112 & 12.2 & $0.338^{*}$ & 0.140 \\
\hline & Shared & 0.048 & 0.116 & & $0.315^{*}$ & 0.127 \\
\hline & None* & $-0.593 * * *$ & 0.152 & & - & \\
\hline ICU length of stay, days & $4-12(>1)$ & $-0.126 * * *$ & 0.036 & 10.9 & $0.072 *$ & 0.041 \\
\hline \multirow{3}{*}{$\begin{array}{l}\text { Risk-conscious behavior- } \\
\text { societal level }\end{array}$} & High & $1.368 * * *$ & 0.113 & 31.2 & $0.720 * * *$ & 0.098 \\
\hline & Moderate & 0.160 & 0.087 & & 0.238 & 0.132 \\
\hline & Low* & $-1.528 * * *$ & 0.119 & & - & \\
\hline \multirow[t]{3}{*}{ Health-conscious behavior } & High & 0.136 & 0.152 & 16.0 & 0.239 & 0.155 \\
\hline & Moderate & $0.676^{* * *}$ & 0.115 & & 0.138 & 0.219 \\
\hline & Low* & $-0.812 * * *$ & 0.102 & & - & \\
\hline
\end{tabular}

Log-likelihood: - 1030, Akaike information criterion: 2099

$I C U$ intensive care unit, $S D$ standard deviation, $S E$ standard error

$* p<0.05, * * p<0.01, * * * p<0.001$

\subsection{Between-Attribute Importance}

Risk-conscious behavior on a societal level had the highest relative importance, followed by age and health-conscious behavior. The relative importance of risk-conscious behavior on a societal level (31.2\%) was almost twice as high as the relative importance of age (16.3\%) and health-conscious behavior (16.0\%). ICU stay had the lowest impact on prioritization for ICU (10.9\%).

\subsection{Interaction}

The differences in preferences between groups for levels within the attribute age was significant $(p=0.042)$. Respondents in the younger and middle age group prioritized younger over older patients (Appendix C in the ESM). However, respondents aged $\geq 60$ years $(n=18)$ had no significant preference for an age group. The age attribute was more important for respondents in the lowest (18.6\%) and middle $(15.9 \%)$ age categories than for respondents in the older age category $(1.7 \%)$.

In contrast with our expectations, a respondent's own profession did not significantly influence preference within the profession attribute $(p=0.250)$.

\section{Discussion}

To our knowledge, this is the first study aiming to elicit the preferences of Dutch citizens on prioritization of patients to the ICU in times of crisis based on non-medical considerations. Even though this was a pilot study, it yielded interesting findings. Preliminary results showed that about twothirds of respondents felt that medical and/or non-medical considerations should play a role in prioritization decisions, which indicates the relevance of the study topic. Risk-conscious behavior on a societal level was the most important attribute in terms of priority setting for admitting patients to the ICU, and patient age and health-conscious behavior on the individual level were the second most important.

Six arguments for prioritization were included in this study. We included three arguments that were in the current framework developed by medical professionals [5] and three that were part of the societal discussion at the time of our study. In the framework, age was included as a measurable attribute of the "fair innings" principle. This principle states that young people should have priority over older people because everyone should receive equal opportunities during their lives and older people have already had more opportunities [5]. Overall, the results of our study showed that younger patients were preferred over older patients, 
although patient age was not important for the respondents in the oldest age group. The other two attributes in the current framework were ICU length of stay as an attribute of efficient care and being a medical professional, as their profession increases their risk of contracting COVID-19. The latter two attributes were less important to members of the public than the following two arguments, which were frequently mentioned in public discussions: (1) risk-conscious behavior at the societal level is important to limit the spread of disease but has far-reaching consequences for people's personal lives, and (2) health-conscious behavior at the individual level was included because individual behavior, such as being overweight and being a smoker, might increase the risk of being admitted to the ICU or influence an individual's chance of recovery $[20,21]$. These two factors, which relate to a person's own responsibility towards contracting and/ or risk of dying from COVID-19, were explicitly excluded from the current framework because personal compliance levels are intrinsically difficult to determine, especially in the current hectic situation before ICU admittance. However, the preliminary results of this study indicate that arguments related to a person's societal or individual responsibility are important from a public perspective, at least according to a convenience sample of the Dutch population.

\subsection{Lessons Learned}

This pilot study revealed points that should be improved in the next survey. We discuss improvements in attribute explanation and operationalization, task design, experimental design, and survey design.

First, the attributes were explained and operationalized based on discussions within the core research team. However, our pilot study indicated that the descriptions of the attributes and the attribute levels, particularly those that were operationalized qualitatively, might be interpreted differently between respondents. Perceptions of what a healthy or unhealthy lifestyle is or what it means to behave in a risk-conscious manner in terms of catching or spreading COVID-19 may also differ. This ambiguity complicates the interpretation of our study findings. In a follow-up study, we would assess these attributes more quantitatively, as per the study by Nelson Laska et al. [22]. Regarding the age attribute, we used broad and unequal intervals, whereas in reality, a 30-year-old patient might be prioritized differently than a 59-year-old patient. In a follow-up study, we would choose smaller ranges or even-point estimates for age.

Second, in the pilot study, we did not include an opt-out option in the choice tasks to clearly represent the ethical dilemma that ICU doctors might face in times of shortage. In a real triage situation, not choosing between patients is not an option in the ICU. Furthermore, in our pilot, including an opt-out option could have resulted in less data on choices between patient profiles. However, a disadvantage of forced questions in a DCE is that respondents are unable to indicate whether they were either indifferent between two profiles or found it too difficult to choose and they would therefore leave the choice to somebody else. In our next survey, we will likely include an option for respondents to indicate indifference and/or include a dual non-response option in which the choice can be made by tossing a coin (as was done by Wilkinson et al. [6]) or opt to leave the choice to a healthcare professional.

Third, although the initial design of the DCE was orthogonal, the final experimental design was not. Almost one-third of the sample that started the survey looked at or read the first page but did not start the actual survey. The Qualtrics system did not account for this in its randomization process. As a result, the choice sets (and thus attribute levels) were not distributed equally over the completed surveys. In the actual survey, we will use block randomization and a quota for the finalized blocks to ensure that the design remains balanced and orthogonal.

Fourth, in the next survey, we aim to collect more background characteristics (e.g., education level, socio-economic status, perceived risk- and health-conscious behavior, health status) to understand the extent to which background characteristics influence respondent preferences for prioritization and the extent to which respondents prioritize patients who are "like themselves".

\subsection{Study Limitations}

Although this pilot study yielded important information on the validity of our survey, it also has several limitations. For instance, our recruitment strategy provided no information on the type and number of people who did not respond to the invitation to participate. Also, about one-third of potential participants dropped out after reading the introduction page before background characteristics were collected. This background information would have enabled us to compare respondents and non-respondents. For instance, if more people with a lower educational level dropped out, this could be an indicator that our survey was too difficult. Likewise, if relatively more older people or people who work in the health sector agreed to participate, this could be an indication of interest in the topic.

Moreover, the current survey included three attributes that are part of the current triage framework and three based on public discussions that were ongoing at the time of the study. We initially identified a broader set of attributes, and the final set was selected based on discussions within the research group. Time limitations meant we did not perform focus groups or interviews in preparation for attribute selection and operationalization. It is important to conduct qualitative studies before DCEs to determine which attributes to 
include and how to operationalize them [23, 24]. Although we believe we captured the most relevant arguments for and against prioritization according to the broad public discussion that was ongoing at the time of the study, we have not extensively tested and compared different ways in which we could have operationalized these arguments.

Furthermore, after our initial pre-test, we used an online format to pilot test the survey and asked the participants to provide feedback on the survey design or other concerns by email. Conducting read-aloud tests or actively following up on participants could have yielded more extensive information on the respondent's understanding of the survey introduction and task design.

Unfortunately, a typing error was made in one of the level descriptions of the choice tasks of the DCE (age $\leq 29$ was accidentally replaced with $\geq 29$ ). Several respondents noticed the error and reported that they ignored it. Excluding this question from the dataset resulted in a minimal change in the analysis results (Appendix D in the ESM). As we think the mistake was either noticed and ignored or not noticed by respondents, we chose to analyze the full dataset.

Finally, our study population is not representative of the Dutch population in terms of sex and age, and this influences the interpretation of the preliminary preferences identified. The fact that younger people and females were overrepresented may be because the researchers used their personal networks to recruit participants. Those networks included more females than males and more younger than older people. Moreover, as the survey was distributed online through certain social media channels, it was only available to respondents who used those platforms. Although no difference in preferences between males and females were found, the preliminary results do show that respondent age significantly influenced prioritization of patients based on their age.

\section{Conclusions}

The public deemed risk-conscious behavior on the societal level, regarding the spread of COVID-19, as most important for priority setting, even though it is currently not included in the third step of the triage framework. Furthermore, the main implication of our pilot study is that we can improve our survey to elicit public preferences for prioritization in the ICU on several aspects. Improvements in task design and attribute operationalization could result in better understanding of the relevant arguments and the decision to be made by survey respondents (external validity), and improvements in experimental design could improve the internal validity of the findings. By collecting more background information on respondents, we could also further explore the preference heterogeneity identified in the pilot test results. The results of such a study in a representative sample of the Dutch population could be used to raise public awareness of the difficult trade-offs required to prioritize patients for hospital beds in times of scarcity and create a feeling of co-ownership of a framework that is developed to make such decisions among the Dutch population.

Supplementary Information The online version contains supplementary material available at https://doi.org/10.1007/s40271-021-00504-4.

\section{Declarations}

Funding No sources of funding were used to conduct this study or prepare this manuscript.

Conflict of Interest MG, IEK, SES, JLT, CGMG-O, and JAvT have no conflicts of interest that are directly relevant to the content of this article.

Availability of Data and Material The datasets generated during and/or analyzed during the current study are available from the corresponding author on reasonable request.

Code Availability The code used for the analyses can be made available upon request for non-commercial use.

Ethical Approval This pilot study was performed in line with the principles of the Declaration of Helsinki. The questionnaire and methodology for this study were approved by the Human Research Ethics committee of the University of Twente (ethics approval number 201377).

Consent to Participate Informed consent was obtained from all individual participants included in the study before they participated in the study.

Consent for Publication All authors have reviewed and approved the manuscript and consented to its publication.

Author Contributions The first four authors contributed equally and are arranged in alphabetical order. They designed the study instrument, collected the data and performed initial analysis and interpretation of the data. The fifth author provided crucial assistance for statistical analysis of the data for the article, and the sixth author initiated the study idea, provided supervision to the first four authors during the study period and provided guidance to the first four authors in writing the manuscript and responding to reviewer queries.

Open Access This article is licensed under a Creative Commons Attribution-NonCommercial 4.0 International License, which permits any non-commercial use, sharing, adaptation, distribution and reproduction in any medium or format, as long as you give appropriate credit to the original author(s) and the source, provide a link to the Creative Commons licence, and indicate if changes were made. The images or other third party material in this article are included in the article's Creative Commons licence, unless indicated otherwise in a credit line to the material. If material is not included in the article's Creative Commons licence and your intended use is not permitted by statutory regulation or exceeds the permitted use, you will need to obtain permission directly from the copyright holder. To view a copy of this licence, visit http://creativecommons.org/licenses/by-nc/4.0/. 


\section{References}

1. World Health Organization. Coronavirus disease (COVID-19) dashboard. 2020. https://covid19.who.int. Accessed 2 Dec 2020.

2. Rijksoverheid. De Nederlandse maatregelen: basisregels voor iedereen. 2020 2020-05-06T19:31. 2020. https://www.rijksoverh eid.nl/onderwerpen/coronavirus-covid-19/nederlandse-maatregelen-tegen-het-coronavirus/gezondheidsadviezen. Accessed $21 \mathrm{Sep}$ 2020.

3. Rijksoverheid. Het coronavirus en zorg op de intensive care (ic-plekken). 2020 2020-04-23T11:31. 2020. https://www.rijks overheid.nl/onderwerpen/coronavirus-covid-19/zorg/ic-plekken. Accessed 10 Sep 2020.

4. UniversitätsklinikumMünster, LNAZ. Handboek gebruik Duitse capaciteit. 2020. https://www.lnaz.nl/cms/files/handboek_gebru ik_duitse_capaciteit_def_juni_2020.pdf. Accessed 13 Oct 2020.

5. Rijksoverheid. Draaiboek 'Triage op basis van niet-medische overwegingen voor IC-opname ten tijde van fase 3 in de COVID-19 pandemie'. 2020.

6. Wilkinson D, Zohny H, Kappes A, Sinnott-Armstrong W, Savulescu J. Which factors should be included in triage? An online survey of the attitudes of the UK general public to pandemic triage dilemmas. medRxiv. 2020:2020. https://doi.org/10. 1101/2020.10.06.20207662.

7. Asghari F, Parsapour A, Gooshki ES. Priority setting of ventilators in the COVID-19 pandemic from the public's perspective. medRxiv. 2020. https://doi.org/10.1101/2020.06.10.20127290.

8. Reed Johnson F, Lancsar E, Marshall D, Kilambi V, Mühlbacher A, Regier D, et al. Constructing experimental designs for discrete-choice experiments: report of the ISPOR Conjoint Analysis Experimental Design Good Research Practices Task Force. Value Health. 2013;16(1):3-13.

9. NOS. Vanaf maandag voorrang voor onderwijs en zorg bij testen. 2020. https://nos.nl/artikel/2348828-vanaf-maandag-voorrangvoor-onderwijs-en-zorg-bij-testen.html. Accessed 18 Sep 2020.

10. NUnl. Brussel: Zorgpersoneel en zestigplussers krijgen voorrang bij coronavaccin I NU - Het laatste nieuws het eerst op NU.nl. 2020 2020-10-15. 2020. https://www.nu.nl/coronavirus/60841 11/brussel-zorgpersoneel-en-zestigplussers-krijgen-voorrangbij-coronavaccin.html. Accessed 15 Oct 2020.

11. Nederlandse Vereniging voor Anesthesiologie. Richtlijn intensive care. 2015. https://www.anesthesiologie.nl/uploads/files/KD_RL_ Intensive_Care_2015.pdf. Accessed 16 Oct 2020.

12. NICE. COVID-19 op de Nederlandse Intensive Cares; Patiëntkarakteristieken en uitkomsten vergeleken met pneumonie patiënten op de IC in 2017-2019: Nationale Intensive Care Evaluatie. 2020. https://www.stichting-nice.nl/COVID_rapport_20210 225.pdf. Accessed 16 Oct 2020.

13. Bottomley C, Lloyd A, Bennett G, Adlard N. A discrete choice experiment to determine UK patient preference for attributes of disease modifying treatments in Multiple Sclerosis. J Med Econ. 2017;20(8):863-70.

14. Kanninen BJ. Valuing environmental amenities using stated choice studies: a common sense approach to theory and practice. The economics of non-market goods and resources. New York: Springer; 2007.

15. Aizaki $\mathrm{H}$. Basic functions for supporting an implementation of choice experiments in R. J Stat Software. 2012 (2012-09-22;50).

16. Johnson FR, Kanninen B, Bingham M, Ozdemir S. Experimental design for stated choice studies. Valuing environmental amenities using stated choice studies: a common sense approach to theory and practice. New York: Springer; 2007. pp. 159-202.

17. Marshall D, Bridges JF, Hauber B, Cameron R, Donnalley L, Fyie K, et al. Conjoint analysis applications in health-how are studies being designed and reported?: An update on current practice in the published literature between 2005 and 2008. Patient. 2010;3(4):249-56.

18. van den Broek-Altenburg EM, Atherly AJ. Patient preferences for provider choice: a discrete choice experiment. AMJC. 2020;26(7):219-24.

19. Gonzalez JM. A guide to measuring and interpreting attribute importance. Patient. 2019;12(3):287-95.

20. Popkin BM, Du S, Green WD, Beck MA, Algaith T, Herbst CH, et al. Individuals with obesity and COVID-19: a global perspective on the epidemiology and biological relationships. Obes Rev. 2020;21(11):e13128.

21. Berlin I, Thomas D, Le Faou A-L, Cornuz J. COVID-19 and smoking. Nicotine Tob Res. 2020;22(9):1650-2.

22. Nelson Laska M, Pasch KE, Lust K, Story M, Ehlinger E. Latent class analysis of lifestyle characteristics and health risk behaviors among college youth. Prev Sci. 2009;10(4):376-86.

23. Vass C, Rigby D, Payne K. The role of qualitative research methods in discrete choice experiments: a systematic review and survey of authors. Med Dec Making. 2017;37(3):298-313.

24. Hollin IL, Craig BM, Coast J, Beusterien K, Vass C, DiSantostefano R, et al. Reporting formative qualitative research to support the development of quantitative preference study protocols and corresponding survey instruments: guidelines for authors and reviewers. Patient. 2020;13(1):121-36. 